\title{
Unilateral renal agenesis: case review of ambulatory pediatric nephrology clinics in Cali
}

\author{
Consuelo Restrepo de Rovetto ${ }^{1}$, Luz Ángela Urcuqui², Maribel Valencia ${ }^{2}$, \\ Iris de Castaño ${ }^{3}$, Alexander Maximiliano Martínez ${ }^{4}$
}

\section{SUMMARY}

Introduction: Unilateral renal agenesis is a frequent renal malformation with incidence of 1 per 1000 live born children. There are no statistics nor protocols to manage and follow-up these patients. Usually asymptomatic, it can be early detected by prenatal ultrasound, allowing opportune detection and adequate follow up. The goal is to describe main features found in children with renal agenesis at four ambulatory pediatric nephrology clinics in Cali, Colombia: Hospital Universitario del Valle (HUV), Club Noel Children's hospital and the private practice of two pediatric nephrologists.

Methods: This is a retrospective descriptive study in a series of cases with congenital renal agenesis diagnosed between January, 1995 and December 2007, of patients under 18 years of age and based on a review of clinical records.

Results: 43 patients were found, $51.2 \%$ males, $88 \%$ from the department of Valle del Cauca. Prenatal diagnoses were conducted in only $21 \%$ of these patients; agenesis was right in $48.8 \%$ and left in $51.2 \%$. In $46.5 \%$, association with other pathologies was found: occult spinal bifida, congenital scoliosis, and Klippel-Feil sequence. Compensatory renal hypertrophy was reported in $39.5 \%$ of the patients, $42 \%$ had episodes of urinary tract infection, $31 \%$ vesicoureteral reflux and $10 \%$ proteinuria. Four male patients $(9.3 \%)$ developed renal failure. The average follow-up was 6.6 years.

Conclusions: Prenatal diagnose was not very frequent in our set of cases. Urinary tract infection and vesicoureteral reflux were common, increasing the risk of renal deterioration. Prolonged follow up is suggested, with unified protocols to prevent renal failure.

Keywords: Unilateral renal agenesis; Prenatal diagnosis; Vesicoureteral reflux; Hydronephrosis; Proteinuria; Renal insufficiency; Body-mass index; Urinary tract infections.

Agenesia renal unilateral: revisión de casos de la consulta nefrológia pediátrica en centros asistenciales de Cali

\section{RESUMEN}

Introducción: La agenesia renal unilateral (ARU) es una malformación con una incidencia de 1 por 1000 nacidos vivos. En Colombia no hay estadísticas ni protocolos para el manejo y seguimiento de estos pacientes. La ARU casi siempre es asintomática y se puede descubrir temprano por ecografía prenatal, que permite el adecuado seguimiento. El objetivo es describir las características principales encontradas en la revisión de historias clínicas de niños con agenesia renal que se examinaron en dos servicios de nefrología pediátrica de la ciudad de Cali: Hospital Universitario del Valle (HUV), Hospital Infantil Club Noel (HICN) y en los consultorios de dos nefrólogas pediatras.

Metodología: Es un estudio descriptivo retrospectivo de tipo serie de casos basado en la revisión de historias clínicas, de pacientes menores de 18 años con diagnóstico de agenesia renal congénita atendidos entre enero de 1995 y diciembre de 2007.

Resultados: Se encontraron 43 pacientes, 51.2\% masculinos. El 88\% procedía del departamento del Valle. El diagnóstico

1. Professor and Chief of Department of Pediatrics, School of Medicine, Universidad del Valle, Cali, Colombia. e-mail:rovettos@gmail.com

2. Pediatrics resident, Department of Pediatrics, School of Medicine, Universidad del Valle, Cali, Colombia. e-mail:lurcuqui@hotmail.com; marivalenciab@yahoo.es

3. Associate Professor, Department of Pediatrics, School of Medicine, Universidad del Valle, Cali, Colombia. e-mail:ircastan@yahoo.com

4. Epidemiology Master's candidate, School of Public Health, Universidad del Valle, Cali, Colombia. e-mail:alexmart75@gmail.com

Received for publication September 8, 2008 Accepted for publication January 12th, 2010 
prenatal sólo se hizo en $21 \%$ de los casos. En $48.8 \%$ de los pacientes la agenesia renal fue derecha y en el resto izquierda. En 46.5\% hubo asociación con otras entidades (espina bífida oculta, escoliosis congénita y secuencia de Klippel Feil). En $39.5 \%$ de los pacientes se vio hipertrofia renal compensatoria, $42 \%$ presentaron algún episodio de infección urinaria, 31\% reflujo vésico-ureteral y $10 \%$ proteinuria; en 4 pacientes $(9.3 \%)$, todos varones desarrollaron falla renal. El promedio de seguimiento fue 6.6 años.

Conclusiones: El diagnóstico prenatal fue poco frecuente en esta serie de casos. La infección urinaria y el reflujo vésicoureteral son altos y aumentan el riesgo de daños renales. Se recomienda el seguimiento extendido en niños con ARU, mediante protocolos unificados para prevenir el deterioro renal.

Palabras clave: Agenesia renal unilateral; Diagnóstico prenatal; Reflujo vésico-ureteral; Hidronefrosis; Proteinuria; Insuficiencia renal; Índice masa corporal; Infecciones del tracto urinario.

Renal agenesis is a relatively common malformation, which appears during embryonic development and may be unilateral or bilateral; the latter is incompatible with survival ${ }^{1}$. The incidence is between $1 / 500$ to $1 / 3200$ births, depending on diagnostic criteria and population selection in various studies ${ }^{1,2}$. Etiology of unilateral renal agenesis (URA) is heterogeneous with environmental and genetic influences. Prenatal factors associated to renal agenesis are diabetes mellitus, alcohol exposure, black race, and young maternal age $(<18 \text { years })^{1}$.

Literature mentions URA as most frequent on the left side and predominating in males with a ratio of $1.2: 1$; it is associated with oligohydramnios or single umbilical artery $^{1}$. It may be associated to other congenital malformations in $64 \%$ of the cases ${ }^{1}$, such as ear pavilion anomalies, atresia of the esophagus, congenital heart disease, spina bifida with meningocele or urogenital malformations such as vesicoureteral reflux and/or hydronephrosis, leading to chronic renal failure ${ }^{1,2}$.URA is usually asymptomatic, but through prenatal ultrasound it is being increasingly recognized ${ }^{1}$.

In these patients, it is fundamental to define: kidney location, the presence of reflux and/or obstruction and to determine the renal function to prevent potential renal damage. Additionally, recommendations should be made to avoid overweight, blood hypertension, dehydration, and the use of nephrotoxic medicines.
The diminished functioning renal mass due to URA may lead to compensatory hypertrophy and hyper filtrationnephropathy ${ }^{1-3}$. Some studies have found a relationship between chronic renal insufficiency and renal agenesis ${ }^{3}$. It has been established that, as time passes, there is greater probability of having compensatory hypertrophy; therefore, it is necessary to conduct long-term follow up studies.

There are no local or national statistics in Colombia to know the frequency, clinical aspects and complications of this anomaly. If the pediatrician or the general practitioner makes the diagnoses, the patient is usually referred to pediatric nephrology for evaluation; for this reason, we have chosen four ambulatory pediatric nephrology clinics: Hospital Universitario del Valle (HUV), Hospital Infantil Club Noel, and the out-patient clinic from two pediatric nephrologists in Cali, Colombia to review the medical records.

Currently, there is no established protocol to study and follow up single-kidney children and there is lack of uniformity in post-natal management of these patients ${ }^{5}$. With the findings from these series of cases with URA and literature review, appropriate recommendations will be produced.

\section{MATERIALS AND METHODS}

Protocol approval by the Ethics Committee of Universidad del Valle and the University Hospital was obtained. Inclusion criteria were: patients with congenital URA under 18 years of age seen at four pediatric Nephrology outpatient clinics between January, 1995 and December 2007. Exclusion criteria were patients with single kidney after nephrectomy or associated to multicystic dysplastic kidney and patients older than 18 years of age.

A list of clinical chart numbers was obtained from the statistics service at the HUV, Hospital Infantil Club Noel, and two private practice pediatric nephrology offices with the diagnoses of: renal agenesis, other kidney hypoplasia malformations, and single kidney. A total of 478 clinical charts with the diagnoses of single kidney; 429 non-congenital single kidney were rejected, leaving 49 congenital single kidneys; 6 of them were rejected because patients were over 18 years old. A total of 43 pediatric patients with diagnoses of URA are reported here. 
Data collection was obtained through a form designed in 3 parts:

1. Patient characteristics: name, gender, age, origin, social security, time of diagnosis, kidney location, and associated anomalies.

2. Diagnostic images: renal ultrasound, voiding cystogram and renal gammagraphy.

3. Most recent physical examination findings (weight, height, blood pressure) and laboratory data such as renal function tests and urinalysis.

Vesicoureteral reflux was graded, according to international classification, in five degrees. Proteinuria was considered positive if present in urinalysis, sulfosalicylic acid test or time urine collection if higher than $4 \mathrm{mg} / \mathrm{m}^{2} /$ day. Serum creatinine is reported in $\mathrm{mg} / \mathrm{dl}$, creatinine clearance in $\mathrm{ml} / \mathrm{min} / 1.73 \mathrm{~m}^{2}$ according to the Schwartz formula or by calculating creatinine clearance with a 24 hour urine collection. Urinary tract infection was positive only with positive urine culture. Time of follow up was considered from date of birth to last clinical visit.

Information from medical records was collected by two pediatric residents from HUV and two pediatric nephrologists (main investigators) in their respective offices.

Statistics. Data obtained generated a database in Epi-Info that grouped diverse information sources; digital errors and obtained registry agreement were verified. Initial data analysis was performed with different variables. Quantitative measurements of central tendency, position, and dispersion were calculated. Quantitative variables were grouped in frequency distribution. Analysis was oriented around answer-generating variables to study goals.

\section{RESULTS}

Table 1 shows main findings in 43 cases. Table 2 summarizes general characteristics of patientes. $51.2 \%$ were male, average age 7 years (ranging from 1 to 270 months). Prenatal diagnosis was done in only $21 \%$ of the cases. Left kidney agenesis was most frequently present, $97.6 \%$ were in normal position, $2.4 \%$ in pelvic position.

Of the total number of patients, $44 \%$ were from the department of Valle del Cauca and $66 \%$ from the city of Cali. Type of social security: $48.7 \%$ from contributing regime, $30.8 \%$ under government protection, and $20.5 \%$ subsidized (Table 2).
Single kidney associated to other pathologies was found in $46.5 \%$ cases: occult spina bifida and congenital scoliosis, 3 cases; anorectal malformations, 3 cases; chromosome syndromes, 2 cases; Klippel-Feil syndrome, 2 cases; cryptorchidie, 1 case; tricuspid insufficiency, 1 case; pre-auricular appendix in 1 case, and 1 case of morbid obesity. No patient with Vater sequence or myelo-meningocele was found. $100 \%$ of associated pathology patients had a post-natal diagnosis (Table 3 ).

One case of hydronephrosis found in renal echography and duplicate urethral system was present. Voiding cystogram was performed in 30 patients $(71.4 \%)$, vesicoureteral reflux was documented n $9(31 \%)$ patients: 6 and grade IV, 2 grade III and 1 grade I (Table 3).

Urinary infection was present in $41.9 \%$ of the patients and it was the most frequent indication for post-natal ultrasound and the recognition of URA (Table 3).

Renal T99 DMSA was performed in 30 patients (73.2\%) being abnormal in 6(21.4\%) with kidney scars. Normal kidney size for age was documented in $67.7 \%$. Kidney hypertrophy was seen by ultrasound or by renal scan in $17(39.5 \%)$ patients (Table 3).

Twenty patients had information concerning proteinuria; it was negative by urinalysis, sulfosalicylic acid, or 24-hour urine collection sample in 18 (90\%) of them. Only two patients had proteinuria, and were the ones with a 16-year follow up, above the 6.7-year average (Table 4).

Four patients had kidney failure (defined as more than $1 \mathrm{mg} / \mathrm{dl}$ creatinine, one of them had an associated cardiopathy (Table 4). Of 29 patients with anthropometric evaluation for age/height, 2 patients were under 2 standard deviations for height (6.9\%). The average follow-up time from date of birth to last control was 6.7 years (range 1 to 192 months).

\section{DISCUSSION}

This present case series has valuable information that may generate questions and suggestions for an opportune diagnosis and adequate follow up in patients with congenital single kidney.

The finding that URA is more frequent in males and in left kidney predominance are similar to literature studies $^{1,2}$.

Despite improved resolution of prenatal ultrasound, in this series, prenatal diagnoses were only performed in 


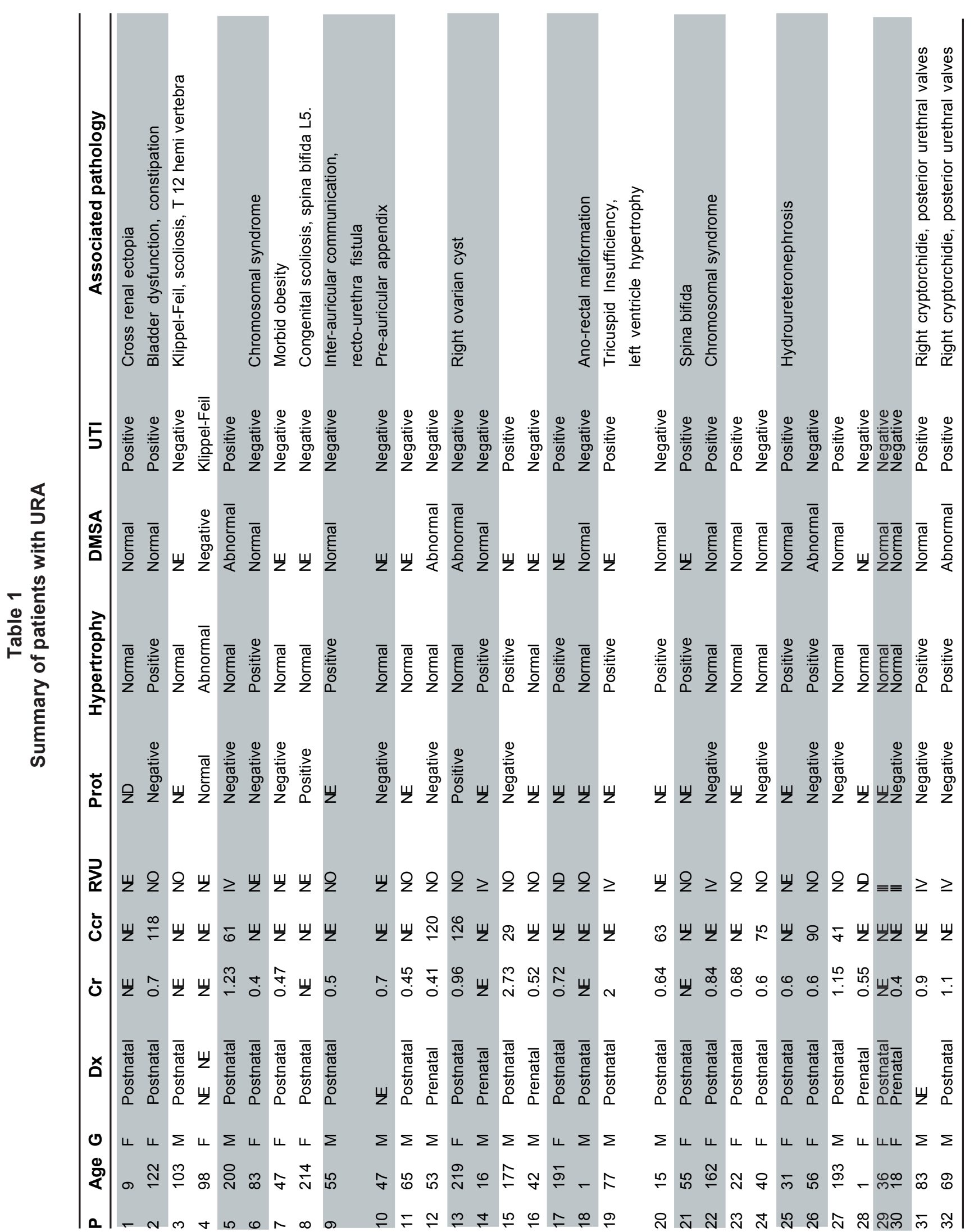




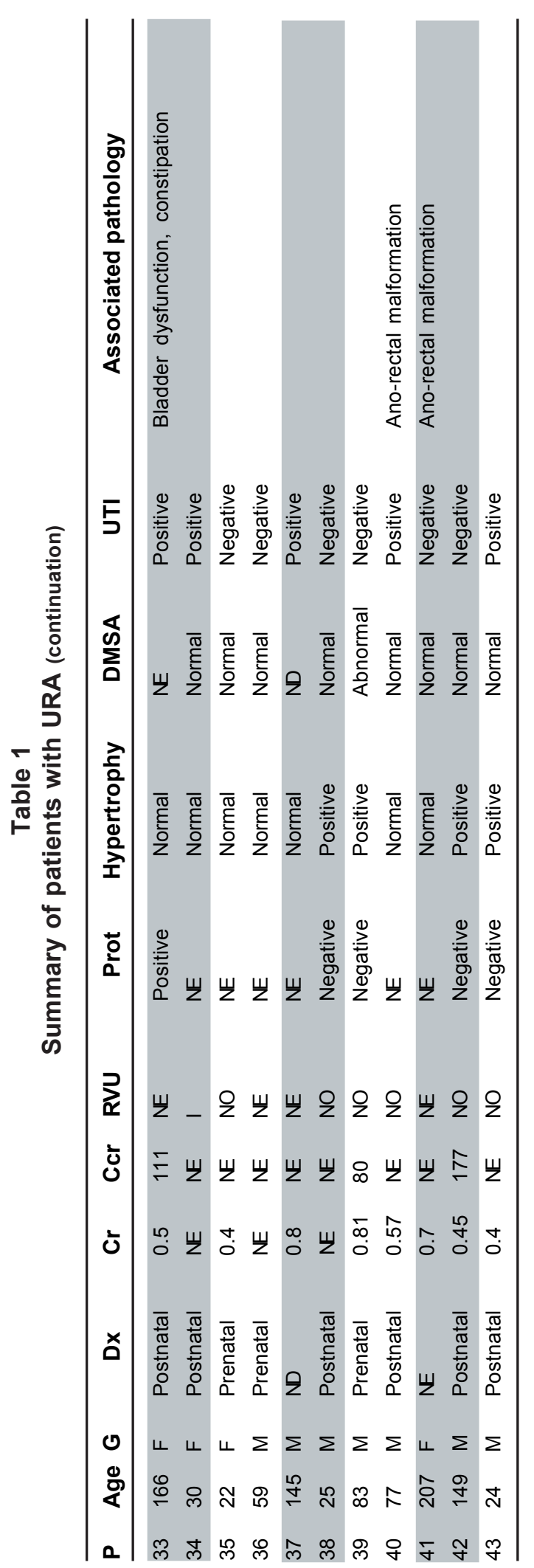

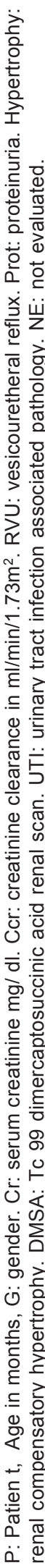

Table 2

General characteristics of patients with URA

\begin{tabular}{llc}
\hline \multicolumn{2}{c}{ Variable } & $\begin{array}{c}\text { Percentage } \\
\text { (N) }\end{array}$ \\
\hline Meanage & & \\
Gender(43) & Male & $51.2(22)$ \\
& Female & $48.8(21)$ \\
Time at diagnosis (38) & Prenatal & $21.1(8)$ \\
& Postnatal & $78.9(30)$ \\
Renal agenesis (43) & Right & $48.8(21)$ \\
& Left & $51.2(22)$ \\
Renal location (42) & Normal & $97.6(41)$ \\
& Pelvic & $2.4(1)$ \\
Place of birth (36) & Cali & $66.7(24)$ \\
& Other & $33.3(12)$ \\
Type of social & Undergovernment & $30.8(12)$ \\
security (39) & protection & \\
& Contributing & \\
& Regimen & $48.7(19)$ \\
& Subsidiated & $20.5(8)$ \\
Pediatric nephrology & HUV & $41.9(18)$ \\
clinic (43) & Nephrology I & $37.2(16)$ \\
& Nephrology II & \\
& HICN & $20.9(9)$ \\
\hline
\end{tabular}

HUV: Hospital Universitario del Valle

HICN: Hospital Infantil Club Noel N: Number of cases

$21 \%$ of them; mayor efforts for routine prenatal ultrasound evaluation should be undertaken to improve detection of renal anomalies, including URA (Table 2). In this sample obtained, we found adequate social security and other regimens represented. Patients were mainly from Cali and most were found at the HUV.

The finding of urine infections in $18(42 \%)$ patients indicates a close association between these two entities; therefore, it is important to have a urine culture done in the follow up for these patients for adequate diagnoses and treatment. Renal ultrasound continues to be a very important study in pediatric patients with urinary tract infections.

The associated anomalies found in this series (46.5\%) are similar to those reported in other series ${ }^{2}$. Cardiac and gastrointestinal malformations are especially common. We also found URA as part of multi-organ syndrome. 
Table 3

Associated pathology, nephro-urological conditions of patients with URA pathology

\begin{tabular}{lcr}
\hline \multicolumn{1}{c}{ Variable } & & Percentage (N) \\
\hline & & \\
Associated pathology (19) & Chromosomal syndrome & $10.5(2)$ \\
& Imperforate anus & $15.8(3)$ \\
Vesicoureteral reflux (29) & Other & $73.7(14)$ \\
Reflux grade (9) & Negative & $69.0(20)$ \\
& Positive & $31.0(9)$ \\
& Grade I & $11.0(1)$ \\
Urinary tract infections (43) & Grade II & $0.0(0)$ \\
Compensatory hypertrophy (43) & Grade III & $22.0(2)$ \\
& Grade IV & $66.7(6)$ \\
Dmsa renal scan (28) & Grade V & $0.0(0)$ \\
& Negative & $58.1(25)$ \\
& Positive & $41.9(18)$ \\
\hline
\end{tabular}

$\mathrm{N}$ : Number of cases DMSA: renal scan with T99 dimercaptosuccinic acid

Table 4

Renal function on follow up

\begin{tabular}{lll}
\hline Renal function (31) & Normal 87\% (27) & Abnormal 13\% (4) \\
Proteinuria (20) & Negative $90 \%(18)$ & Positive 10\% (2) \\
Hypertension (30) & Negative $96.6 \%(29)$ & Positive 3.3\%(1) \\
Mean follow-up time (years) & 6.67 & \\
\hline
\end{tabular}

Knowledge of associated abnormalities enables health professionals to search for associated renal pathologies like URA, increasing echography evaluation in these patients prognosis of URA depends on the presence and severity of associated anomalies and the status of the remaining kidney ${ }^{1,2}$.

Many reports have emphasized on the importance of a complete urologic evaluation of the contralateral renal $\operatorname{tract}^{1,2}$. Reported abnormalities include renal malrotation, ectopia, ureteropelvic junction obstruction, ureterovesical junction obstruction, ectopic urether, and dysplasia ${ }^{1}$. If hydronephrosis is present in ultrasound, obstruction or reflux should be evaluated. Increased renal echogenicity in ultrasound might suggest dysplasia ${ }^{2}$.
Gammagraphy with T99 DMSA is a highly useful test in these cases, allowing to rule out ectopic kidneys and providing renal function information ${ }^{1,2}$. According to findings, other studies will be complemented. Six patients in our series had gammagraphy anomalies and 2 of them with a grade IV reflux. Gammagraphy anomalies indicate voiding cystogram and closer renal function follow ups.

Miccional cystography was done in $71.4 \%$ of cases and $31 \%$ of them had vesicoureteral reflux (8 patients) grade III and IV, suggesting its importance in detecting this pathology. These findings have been described in other studes ${ }^{1,2}$ and some authors recommend a routine miccional cystography in all URA patients. We consider 


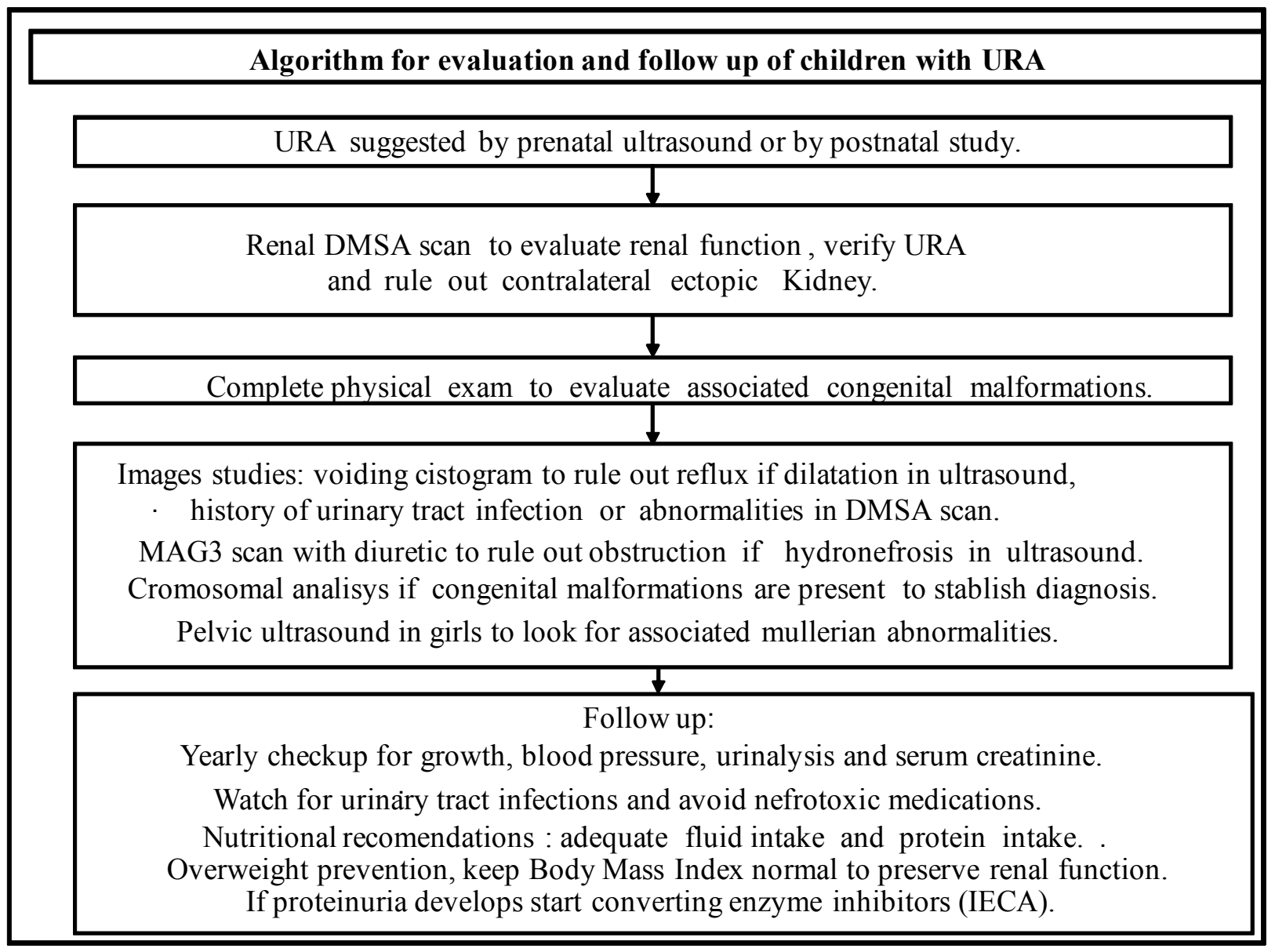

Graph 1. Algorithm for evaluation and follow up of children with URA

that voiding cystogram should be done to detect reflux if dilatations are found in renal ultrasound or changes in renal DMSA scan, suggesting pyelonephritis or if the patient has a later urine infection at follow up.

Renal compensatory hypertrophy was found in $39.5 \%$ of the cases. These have even been reported in prenatal stage or early after birth ${ }^{1}$. In adults, 20 to $40 \%$ of individuals with URA have significant increase in renal length above the upper normal age-adjusted limits. The tendency to increase in length can be viewed as a positive adaptive response; such compensatory growth can be detrimental in the long term with development of proteinuria, hypertension, glomerulosclerosis and progressive renal failure ${ }^{2-4}$.

Proteinuria was detected in $10 \%$ of the patients. It is an important clinical marker for renal function and for an incipient hyper filtration process due to compensatory hypertrophy. Follow up with a yearly urinalysis or microalbuminuria, as with diabetic patients to detect hyperfiltration is recommended. Patients with URA and proteinuria who had renal biopsy are found to have glomeruloesclerosis ${ }^{2}$. Adults reported with URA and using converting enzyme inhibitors to reduce proteinuria ${ }^{4}$ and having an angiotensin II blockage showed less renal function deterioration ${ }^{4}$. Experience with children is limited but if proteinuria is detected, it should be considered.

Patients with proteinuria had a 16-year follow up, suggesting that proteinuria may appear with time; implying a long-term follow up; ideally, with a defined protocol. Prolonged follow up is essential due to higher risk of hypertension and chronic renal insufficiency ${ }^{1,3,4}$.

In four patients serum creatinine was $>1 \mathrm{mg} / \mathrm{dl}$, alerting the importance of monitoring renal function in children with URA. Early diagnoses of urinary infections and adequate management of reflux or obstruction are essential to preserve renal function.

In obstructive uropathy, a correction should be done 
to prevent chronic renal insufficiency. In our cases, we had one case with late management of hydronephrosis and chronic renal insufficiency at 14.7 years of age.

Weight control is fundamental. There is adult evidence that increasing BMI implies more risk of renal function deterioration. González ${ }^{4}$ in a series of 33 adults with URA found that those with high blood pressure and proteinuria were present in those with higher BMI. In our study, it was not possible to conduct a general analysis of the group as for the nutritional state since only 22 patients had full data.

There is no uniformity in follow up of patients with URA $^{5}$. A revision by Ahmed and Lakshman ${ }^{5}$ interrogated doctors on how they made a control of these patients and only $49 \%$ did occasional studies such as postnatal ultrasound, renal scan with DMSA or MAG3, or voiding cystogram; only $7 \%$ will refer to specialist ${ }^{5}$.

In our series and in series published, due to chronic renal failure and associated anomalies, we recommend periodic evaluation and long-term follow up of these patients by pediatric or adult nephrologists ${ }^{1,3,4}$.

\section{RECOMMENDATIONS}

We propose the algorithm in Graph 1 for evaluation and follow up of children with URA.

Addressing the different concepts among medical professions ${ }^{5}$ and described risks in patients with URA in the present pediatric series and other adult series ${ }^{3,4}$, we consider that life-long follow-up control should be performed by pediatric or adult nephrologists since hypertension, proteinuria, and renal insufficiency have been reported in long-term studies ${ }^{3,4}$.
Besides, we recommend increase use of prenatal ultrasound for early detection of any type of urologic malformation, including URA.

Conflict of interest. None of the authors has conflicts of interest related to this study.

\section{ACKNOWLEDGMENTS}

We thank Dr. Carlos A. Echandía, Associate Professor, Department of Pediatrics, Faculty of Health, Universidad del Valle, Master's in Epidemiology, for his collaboration in the initial protocol and questionnaire. We also express gratitude to the members of archives at Hospital Universitario del Valle, for their effective and diligent work in facilitating clinical charts of singlekidney patients. Thanks also go to the pediatrics service, Hospital Universitario del Valle, Hospital Infantil Club Noel, and private practice patients who made this study possible.

\section{REFERENCES}

1. Yalavarthy R, Parikh CR. Congenital renal agenesis: a review. Saudi J Kidney Dis Transpl. 2003; 14: 336-41.

2. Woolf AS, Hillman KA. Unilateral renal agenesis and the congenital solitary functioning kidney: developmental, genetic and clinical perspectives. BJU Int. 2007; 99: 17-21.

3. Argueso LR, Ritchey ML, Boyle ETJr, Milliner DS, Bergstralh EJ, Kramer SA. Prognosis of patients with unilateral renal agenesis. Pediatr Nephrol. 1992; 6: 412-6.

4. González E, Gutiérrez E, Morales E,Hernández E, Andres A, Bello I, et al. Factors influencing the progression of renal damage in patients with unilateral renal agenesis and remnant kidney. Kidney Int. 2005; 68: 263-70.

5. Ahmed A, Lakshman R. Antenatally diagnosed single kidney: lack of uniformity in postnatal management practice. Arch Dis Child. 2006; 91: 543 . 